\title{
Sizing and Balancing of a Semi-Automated Line for Automotive Electric Motors by Means of Ergonomic and Performance Analysis
}

\author{
Paolo Righettini, Roberto Strada, Stefano Togni, Filippo Cortinovis, Cristiano Fissore
}

\begin{abstract}
Smart mobility has become more and more critical during the last years, being one of the most keyways to reduce and regulate vehicular traffic and relevant environmental pollution. In this context, the University of Bergamo participates in a broad project promoted by Brembo S.p.A., a well-known Italian automotive company specialized in vehicles' braking systems, aimed at the synergistic development of the design of brushless electric motor for braking and the relevant production process. The present paper concerns the design phase of the manufacturing line and, in particular, the sizing and the balancing of the line itself. The production line is a semi-automated one, hence many different scenarios have been considered, according to the number of operators and to the number of machines assigned to each operator. The method applied for the design process is based on the application of discrete - event simulations; as a tool for the analysis of each scenario, FlexSim software has been used. The high number of workstations involved, the evaluation of the ergonomics and productivity of each single task, and the use of a wide range of indexes as assessment criteria lead to an activity characterized by a high level of complexity. The operators' ergonomic analysis refers to the ISO standard related to the evaluation of the ergonomic risks and on the operator's walking distance covered during the shift. The paper ends showing how it is possible to define the best scenario, taking into consideration such indexes which concern productivity, ergonomics, optimal balancing of the operators and the distance travelled by the operators during the shift.
\end{abstract}

Keywords: semi-automated line, sizing, balancing, standard ISO, discrete-events simulation.

\section{INTRODUCTION}

The smart mobility has become one of the most important things to deal with to reduce the environmental impact that the most common mean of transport, the road vehicle, causes

Revised Manuscript Received on April 25, 2020.

* Correspondence Author

Paolo Righettini*, department of Engineering and Applied Sciences, University of Bergamo, Dalmine (BG), Italy. Email: paolo.righettini@unibg.it

Roberto Strada, department of Engineering and Applied Sciences, University of Bergamo, Dalmine (BG), Italy. Email: roberto.strada@unibg.it Stefano Togni, department of Engineering and Applied Sciences, University of Bergamo, Dalmine (BG), Italy. Email: stefano.togni@unibg.it

Filippo Cortinovis, department of Engineering and Applied Sciences, University of Bergamo, Dalmine (BG), Italy. Email: filippo.cortinovis@unibg.it

Cristiano Fissore, Advanced R\&D. Brembo S.p.A., Stezzano (BG), Italy. Email: Cristiano_Fissore@brembo.it

(c) The Authors. Published by Blue Eyes Intelligence Engineering and Sciences Publication (BEIESP). This is an open access article under the CC BY-NC-ND license (http://creativecommons.org/licenses/by-nc-nd/4.0/) due to its weight that requires a significant consumption and waste of energy to the systems of braking and traction. At this aim, the present paper regards the analysis of a semi-automated line for the manufacturing of electric motors for the next generation of braking systems completely electrified. This line has been developed to be placed in a laboratory for the series and the prototyping production, and the sustainability of its processes has been achieved by the use of the technologies that have been selected because of two important characteristics:

- their reduced consumptions: of materials and of energy.

- their flexibility for the prototyping to conduct the tests in the laboratory.

The design of the motors and of the relevant production line have been developed in parallel according a synergistic approach that can be reassumed with "integration" and that has given to the project the name INPROVES, as the acronym of "integration of product and of process for the manufacturing of road vehicles".

The world leader in the production of braking systems and well - known Italian company Brembo S.p.A. has led the project by the cooperation of many industrial stakeholders, innovative starts up and the University of Bergamo. Each partner has provided his contribution in terms of knowledge, competence, and of manufacturing according to his specific area of know - how. In this instance, the University of Bergamo has developed the description of the available technologies, that could have been used in the manufacturing of the motors, in terms of their performance, flexibility and consumptions.

Those motors are brushless, and their production is based on the completion of their main subassemblies here reported:

- Stator: it is made by the winded poles that have been welded to be inserted in a housing.

- Rotor: it is the component that allows the electro magnetic energy to be converted in mechanical.

- Flange: it is designed to be the see of the rotor and to be assembled with the stator for the completion of the motor.

Two sizes of brushless motors have been designed, but still maintaining the same working procedures and the same types of subassemblies in compliance with the requirement of flexibility of the line. These two sizes are the result of the optimization of the motors related to their specific application on the vehicle because, according to the rear and the front braking systems, they must provide different ranges of values of braking forces [1]. 


\section{PRODUCTION PROCESS AND LINE}

The above-mentioned working procedures can be represented according their relevant technology in the form of the Process Flowchart reported in Fig. 1, that describes the main macro - phases of the manufacturing of the motors.

These phases have been pointed out using the legend reported in the following Table I:

Table I: - Legend of the Process Flowchart related to the technologies

\begin{tabular}{|c|c|}
\hline \multicolumn{2}{|c|}{ LEGENDA PROCESS FLOWCHART } \\
\hline Sub-process flow of the stator \\
\hline Sub-process flow of the rotor \\
\hline Sub-process flow of the flange \\
\hline Sub-process flow of the motor \\
\hline
\end{tabular}

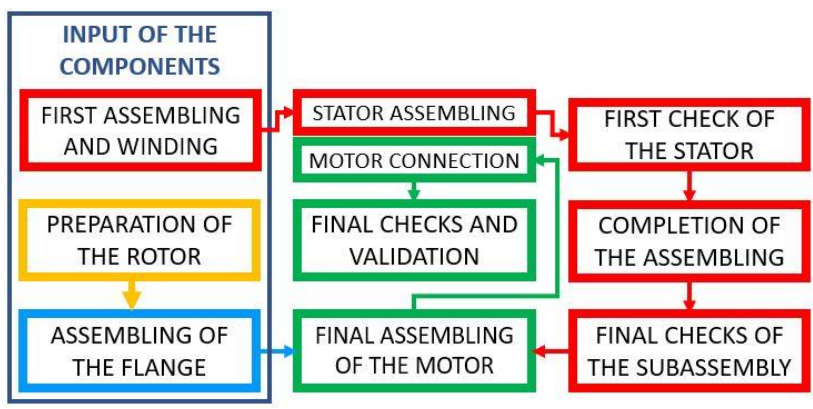

Fig. 1. Process Flowchart related to the manufacturing procedures. It outlines the four main sub-flows of the line.

Each block reported in figure summarizes the procedures and the sequences for more than one workstation, and they are connected to one other in order to simplify the comprehension of the fluxes of the components through the line [2]. In fact, the technologies have been firstly divided according to the relevant phase of assembling and then the equipment needed to provide their work has been designed.

In this way the relevant workstations have been designed to guarantee their management for:

- The manufacturing of batches of motors.

- The manufacturing of prototypes for testing

An introduction of the relationships existing between each workstation is provided in the following Process - Flowchart reported in Fig. 2, in which each of them is represented by an alphanumeric code, and the mains interweaving of fluxes are reported.

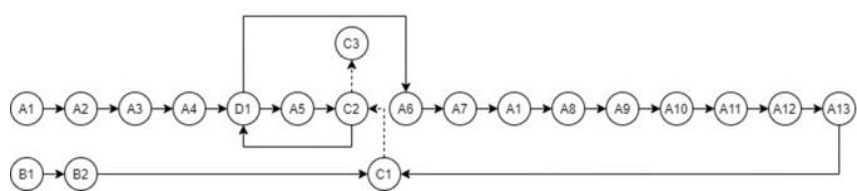

Fig. 2. Process Flowchart according to the workstations of the line.

A workstation implies a definite sequence of procedures for the manufacturing that must be performed by the machine or by the operator. However, since some machines work autonomously requiring a reduced manual cycle time whereas some others are semi - automated, the operators can be stressed differently if they are assigned to the first or the second ones [3].
In the present paper, the distribution of the tasks among the operators is called scenario. In this instance, a quantitative approach has been applied to obtain a well - sized and well balanced line by the quantitative evaluation of the ergonomic effects and of the performance achieved by each scenario [4][5]. As a matter of fact, even though the line has been completely designed in each of its parts [1], its behaviour has not already been forecast varying the number of operators and their tasks.

As above - mentioned, the whole line will be placed in a laboratory for series and prototypes production. In this case, the area occupied by the equipment has an impact on the performance of the operators because they must complete these two main types of activity:

- Material handling: the operators are expected to provide the machines with the raw materials they need or to collect, through the line, the output of one workstation and to put it as the input of another one as stated by the Process Flowchart.

- Technical operations: according to the level of automatization of each machine, the tasks assigned to the operators can imply specific sequences of manufacturing not designed to be performed by the machine because related to a manual action.

The overall number of activities that each operator can complete during a shift is proportional to his total available time reduced by the time necessary for the travels and needed by the machines. In fact, as the operator has loaded the machine, its automatic manufacturing cycle takes place and, as long as it works, the operator can travel to perform other activities.

\section{METHODS}

Since each motor made by the semi-automated line of manufacturing has been worked by both the machines and the operators, the overall productivity of the line is strictly dependent on both behaviours that can be measured by the following parameters [3]:

- Saturation rate of each machine: it measures, in form of a percentage, the time in which the machine is autonomously working without occupying the operator.

- Utilization rate of each operator: it measures, in form of a percentage, the time in which the operator is involved in acting actions at a workstation. This value also allows the calculation of the percentage of idle rate, that measures the percentage of time in which the operator is completely free.

- Distances covered: it measures, in meters, the overall distance covered by foot by the operator during his shift, and it is also provided in form of percentage of time to indicate the quantity of time that has been spent.

- Handling rates: it measures, in form of percentage, the time that has been spent by the operator in handling the products during his shift.

Their values have been firstly used for the ergonomic analysis according to the ISO 11228-3:2007 [6], the ISO standard related to the evaluation of the ergonomic risks of the operator, in particular due to those activities that require

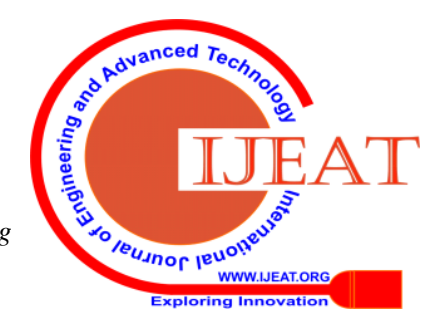


the operator to assume awkward posture or to complete them with high frequencies or accuracies [7]. This ISO standard states numerous variables, each of them belonging to a specific characteristic under scrutiny, that must be studied in their development during the shift. Since the shift can be scheduled in different ways and each operator can be assigned to different workstations, these variables have been used to evaluate, on one hand, the ergonomic adequacy that the machines allow to the operators and, on the other, the stressing conditions that may be due to high productions rates. In this contest, this analysis provides the good practices to study the peculiarity of a shift in order to evaluate its compliance with the ISO 11228-3:2007 and to measure the performance achieved.

The significant quantity of data, that have been collected by the measuring of the variables, have been used by a sequence of further steps of analysis to compare the results with the expected achievements, that are the sizing and the balancing of the semi-automated line [3].

The variables have been measured according to different shifts, each of them characterized by a specific assignment of:

- Number of operators from 1 to 4 : in this instance, the line managed by only one operator describes exclusively the shift of validation of the machines, that is the first shift scheduled after the assembling of the line and whose aim is the checking of the functionalities of the workstations and of their equipment in order to verify the compliance with the requirements stated by the design and reported in the technical documents of purchasing. More specifically, the validation requires the completion of the overall cycle of manufacturing of all the products, that must be controlled according to their technical requirements, and in the meantime even of the checking of the data provided by the software. All the other settings describe shifts of manufacturing.

- Number of machines assigned to the operators: each machine implies a specific sequence of tasks to be performed to complete its cycle of manufacturing. Even though some tasks are performed autonomously by the machine, some other require the manual contribution of the operator.

For this reason, each shift implies a different association among operators and type and number of tasks, that has been made by the assignment of each operator to a specific area of competence, related to one or more than one subassembly previously stated, as well as to one or more than one technological process previously introduced by the Process Flowchart. Each shift characterized by one of these specific associations is called "scenario" [4][5].

\section{SIMULATIONS}

These principles have led the development of a set of scenarios to be analysed according to the previous targets. Since each scenario is made by a complex interweaving of fluxes of manufacturing, the way in which it is described and analysed become paramount to obtain a model of the scenario compliant with the relevant real shift [3][8]. For this reason, the software FlexSim has been selected because its being a tool of simulation of manufacturing processes which adaptability has been particularly well demonstrated by the creation of a unique model, describing all the requirements of the line, adaptable to the scenario under scrutiny [9].

More specifically, the present paper implements a methodology of analysis based on the application of discrete - event simulations in the manufacturing industries whose main topics have been introduced in other works [9] [10] [11] [12] [13] [14] [15]. Even though the literature available describes the efficacy of the application of discrete - event analysis for the simulation and the balancing of manufacturing plants, the project under analysis in the present paper is characterized by a higher level of complexity due not only to a higher number of workstations studied for the production processes, but also to the further evaluation of the ergonomics and of the productivity of each single tasks and to the achievements that the overall line of manufacturing has reached through the balancing by ISO standard and custom solutions. The set of scenarios has been developed according to evaluate the effects that a significant variation of resources available may have on the productivities of the workstations and on the ergonomic adequacy of the working conditions of the operators [6] [7]. The different scenarios, that are graphically described in the following figures from Fig. 3 to Fig. 12, have been here reported by the use of the simplified "legend scenario" in Table II. As described, each scenario may have a different number of operators assigned to work at specific workstations and in their relevant working areas. However, the operators may travel across other areas only in case of intertwining fluxes.

Table II: Legend of the scenario

\begin{tabular}{|c|}
\hline \multicolumn{1}{|c|}{ LEGENDA SCENARIO } \\
\hline
\end{tabular}

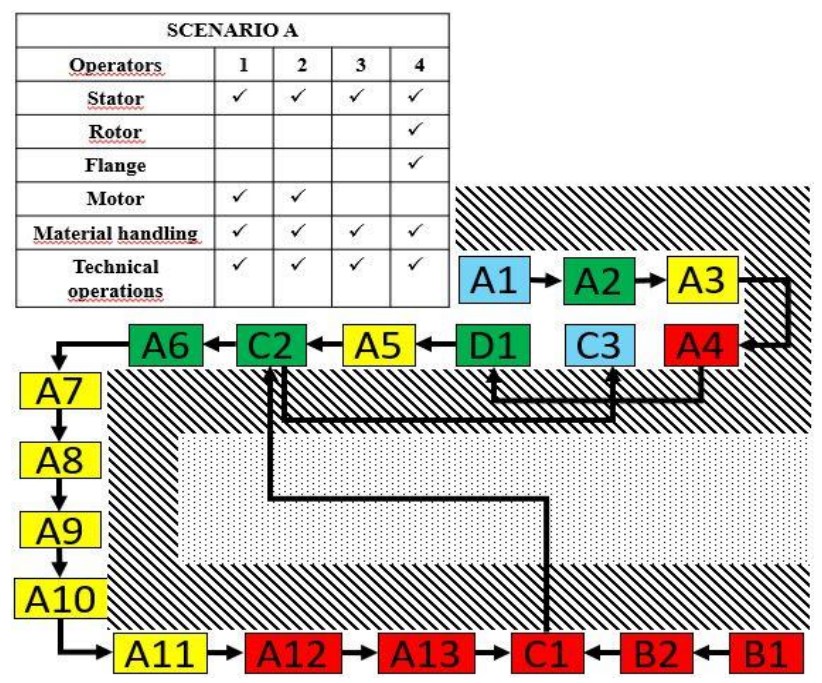

Fig. 3. Scenario A: assignments and subassemblies managed by the operators.

Published By:

Blue Eyes Intelligence Engineering \& Sciences Publication

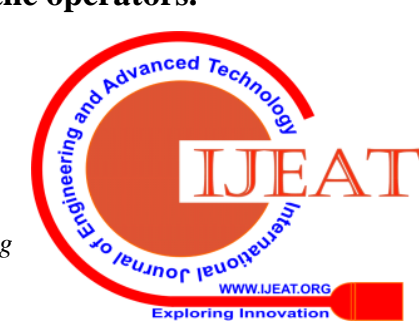


Sizing and Balancing of a Semi-Automated Line for Automotive Electric Motors by Means of Ergonomic and Performance Analysis

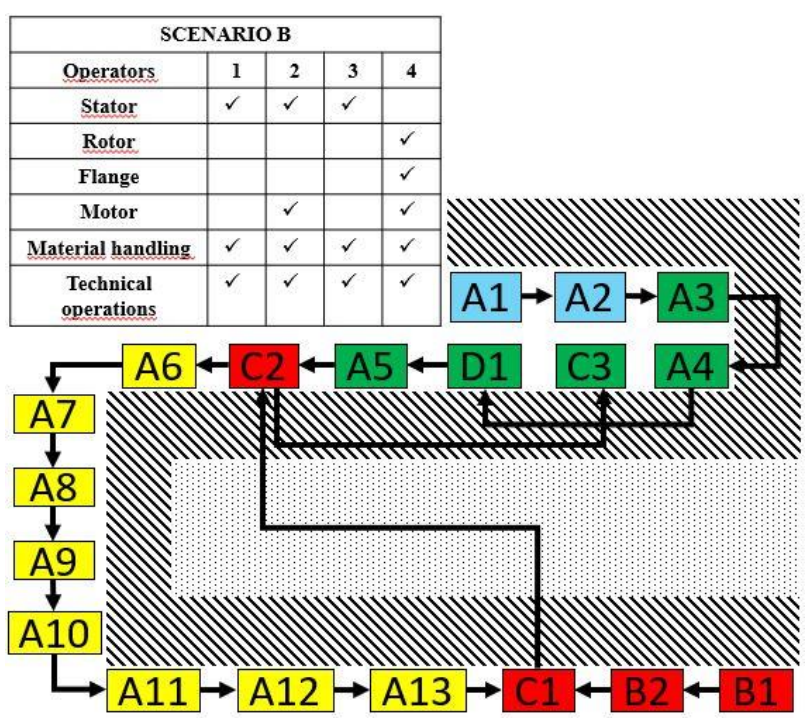

Fig. 4. Scenario $B$ : assignments and subassemblies managed by the operators.

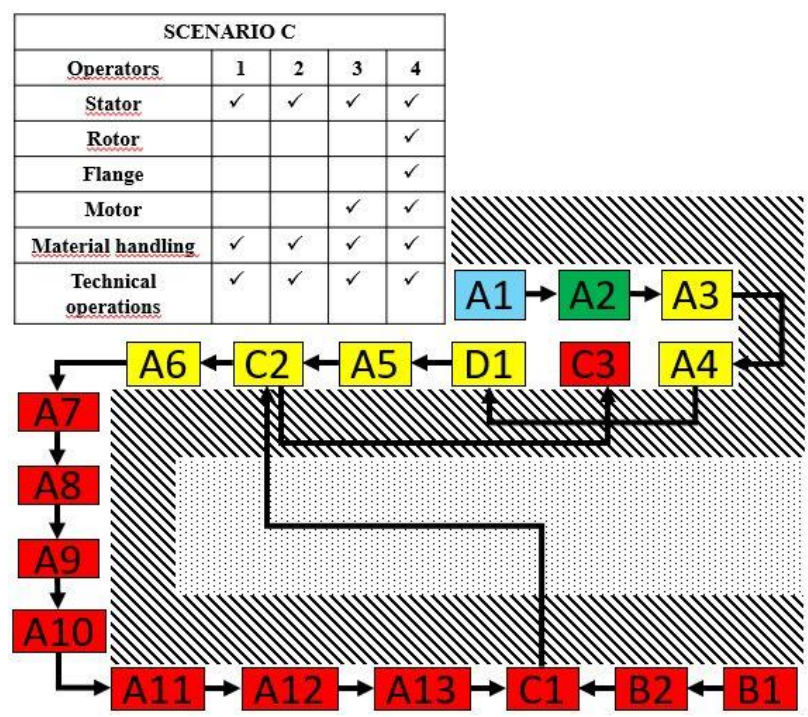

Fig. 5. Scenario $C$ : assignments and subassemblies managed by the operators.

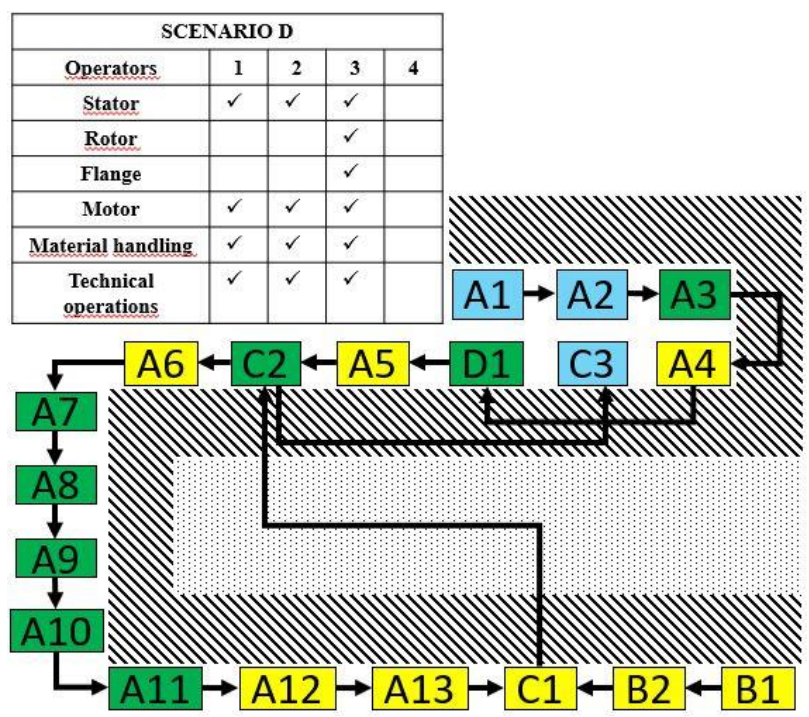

Fig. 6. Scenario $D$ : assignments and subassemblies managed by the operators.

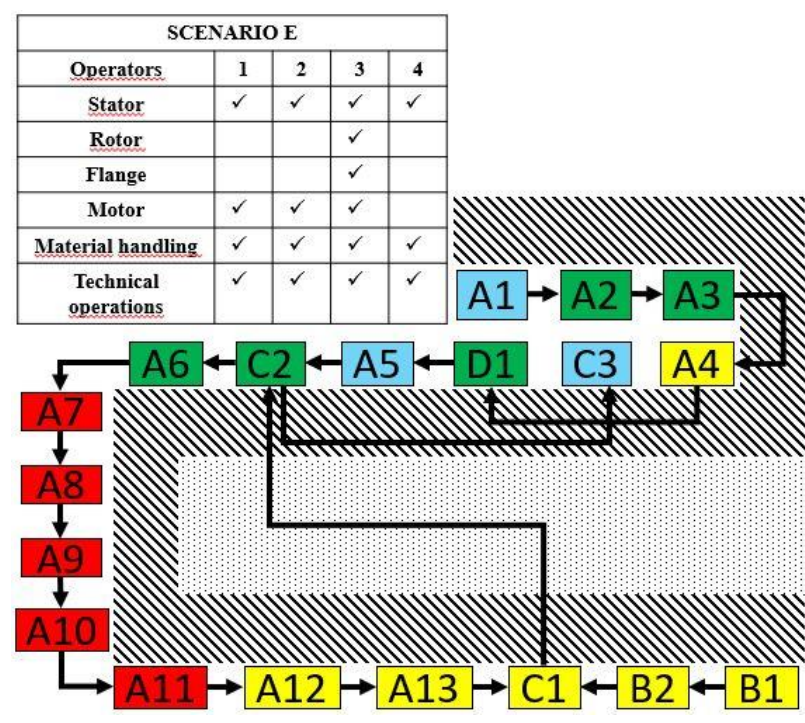

Fig. 7. Scenario $E$ : assignments and subassemblies managed by the operators.

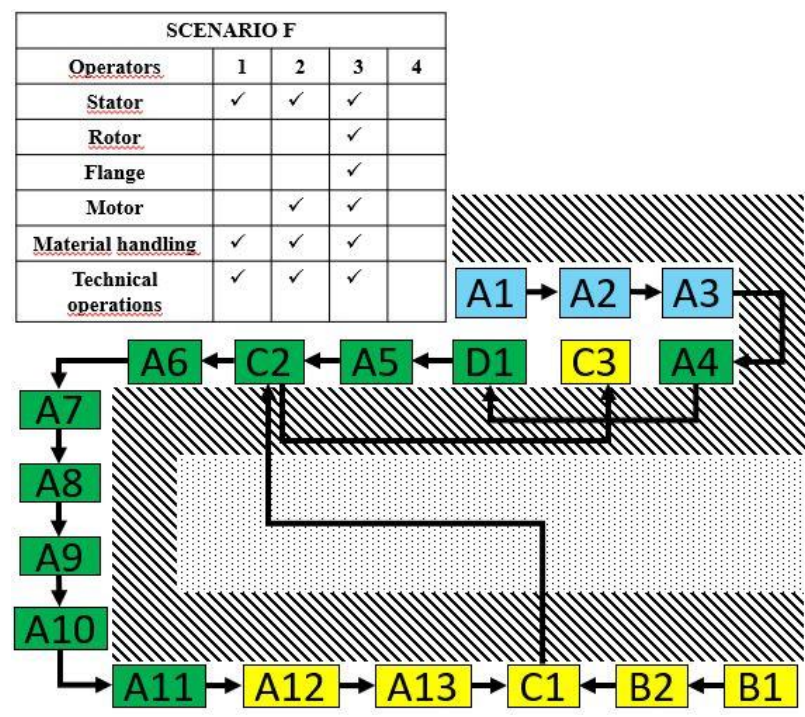

Fig. 8. Scenario $F$ : assignments and subassemblies managed by the operators.

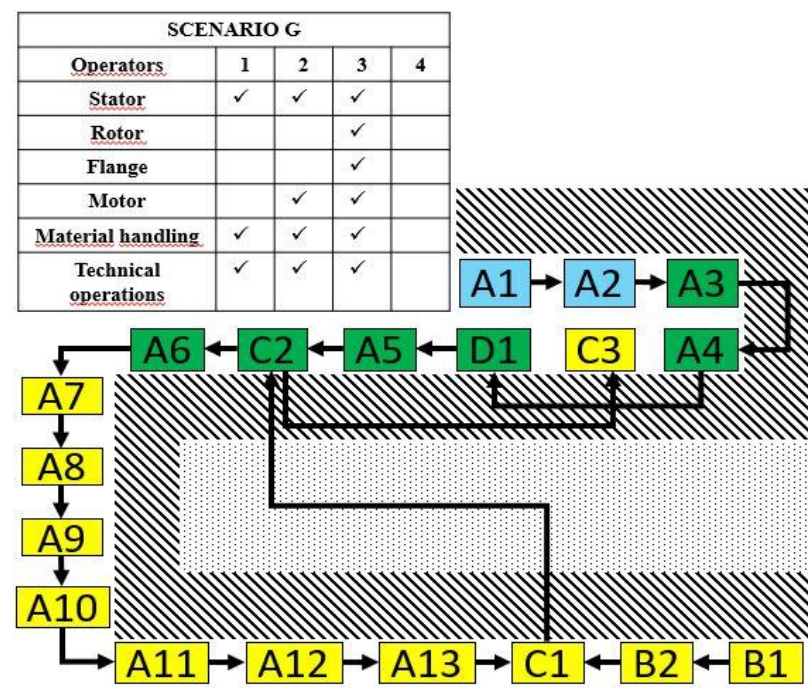

Fig. 9. Scenario $G$ : assignments and subassemblies managed by the operators.

Published By:

Blue Eyes Intelligence Engineering \& Sciences Publication 


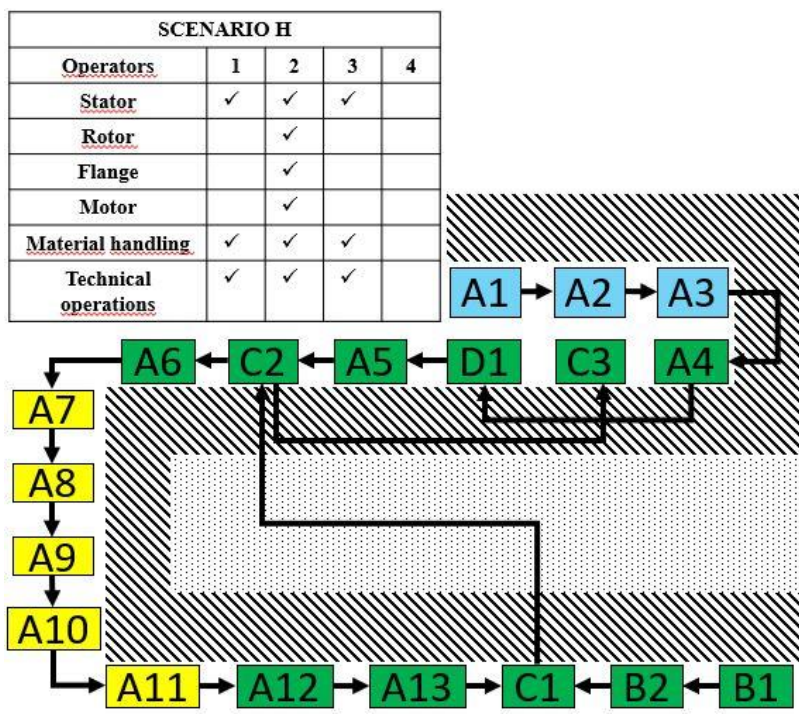

Fig. 10. Scenario $H$ : assignments and subassemblies managed by the operators.

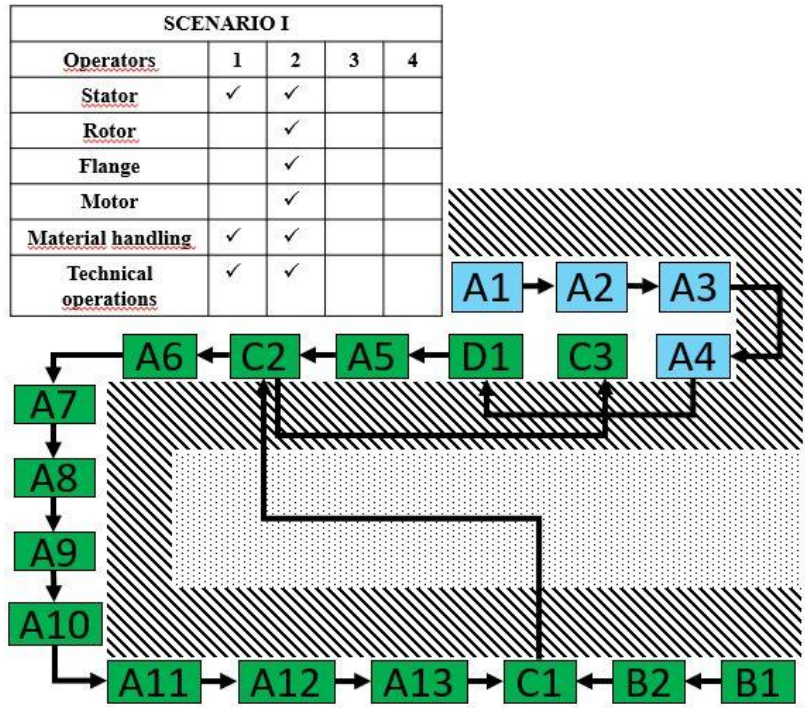

Fig. 11. Scenario I: assignments and subassemblies managed by the operators.

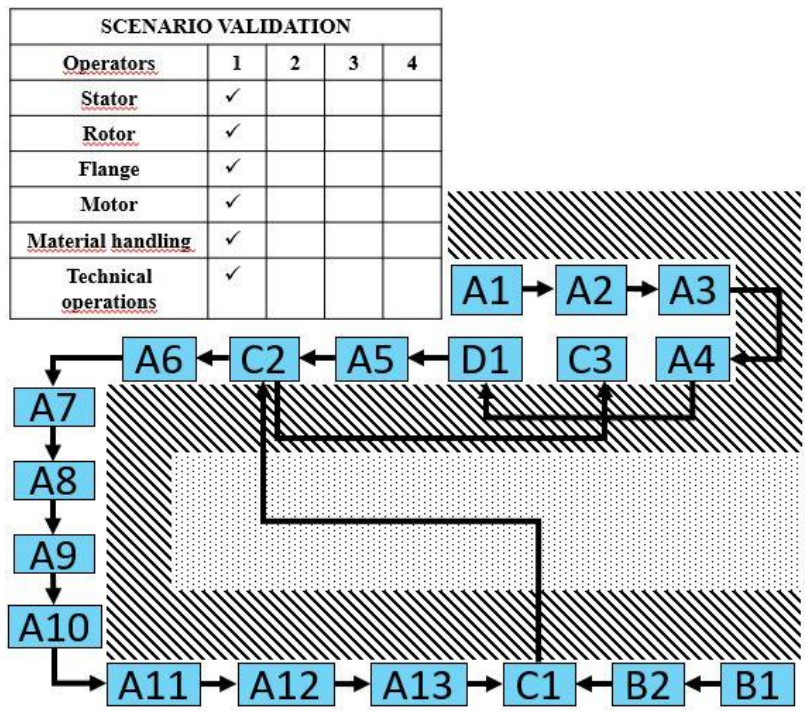

Fig. 12. Scenario validation: assignments and subassemblies managed by the operators.
As previously stated, the project, oriented to both the prototyping and the manufacturing of brushless motors for the new generation of braking systems, is also oriented to the study of the productivities achieved by the technologies selected, by the operators and by the workstations. The first step to conduct this analysis is the modelling of the line by the use of FlexSim software, capable of reproducing the causes and measuring the effects of the different sets of resources available in the scenarios according to the above - mentioned parameters, that, while testing each scenario, allow to evaluate the working conditions of the employees and the machines.

These parameters have been used to conduct the sizing and the balancing of the line through the application of the ISO standard and, more specifically, of the ISO 11228-3:2007 which states the good practices to measure and evaluate the ergonomic risks that may affect the operators [6] [7].

The targets that have been achieved using this method are pointed out in the following:

- The performing of an equal load of work due to the tasks by each operator, known as the balancing.

- The calculation of the number of operators that allows the previous condition, known as the sizing.

- The lower distance covered by each operator due to the travels and the material handling, being the stationary working condition preferred.

In this instance, the main target to be achieved is a semi-automated line with a balanced assignment between tasks and resources, whose number must be sized in order to guarantee both the ISO standard and the expected productivities [3].

The study of each scenario, of its machines, its resources and of their relationships, has been conducted by the simulation of the relevant model built by the use of the software FlexSim, a tool specialized in the simulation of the behaviours of the manufacturing plants. First of all, the model of the line must be provided with:

- The same number of workstations stated in the project.

- The same dimensions of the machines and their displacement in compliance with the line layout.

- The same functionalities of the workstations divided according to the automatic and the manual tasks.

- The same cycle times of the real manufacturing.

Even the machines and the subassemblies have been provided with the real shapes in order to optimize the compliance with the real equipment.

In so doing, the workstations have been set with all the necessary functions to manage their relevant inputs and outputs stated in the Process Flowchart by the use of specific tools, available in the software and capable of reproducing the following paramount steps of the process:

- Technologies used in the manufacturing: each action made by the machine can be described by the tool called "Processor" whose functions stands for an action capable of modifying the shape of the components or checking their quality by means of systems of control such as those of vision. This tool can also simulate an automatic process of the line in which the machine must work a single component.

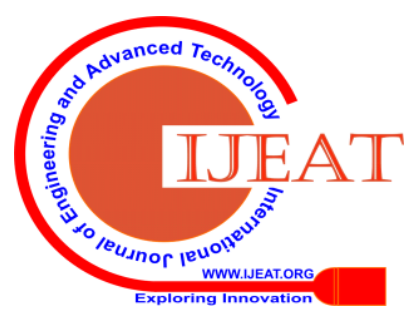


- Assembling and disassembling: the tools that have been selected to perform these phases are the "Combiner" and the "Separator" respectively. They can be used by the operator for the manual phases but be also used for the autonomous tasks of the machines, such as the welding phases. In this instance, more than one input and output can be simultaneously managed.

- Batch processing: one of the aims of the line is the manufacturing at one time of a definite number of motors, known as batch. It is guaranteed by the tool "Queue" because capable of collecting the required number of products before releasing them to the relevant workstation, and of being used as the buffer.

- Physical paths: as before mentioned, the operators must travel along the line according to the scheduled tasks. In this instance, FlexSim allows the evaluation of the overall distance covered by the introduction of the physical paths defined according to the layout to obtain a reliable measure only if the operators move along them. While walking along these paths, their overall walking distance increases as a consequence of:

○ The completion of the cycle time and the continuing at the next workstation.

- The interruption of the cycle time due to a pre-emptive request of another workstation, in this case the pre-emption is assigned according to the First In - First Out (FIFO) logic.

During the simulation of the shift, the software schedules the activities of the operators according to the tasks stated in the Process Flowchart and their relevant pre-emptions that have been introduced by a unique index of priority.

As a matter of fact, the workers are expected to remain at the workstation for a total amount of time equal to the overall manual tasks, and are not required to wait the completion of the automatic operations except in case they have no other tasks to deal with.

\section{PARAMETER ESTIMATION}

All what has been previously stated allows the building of the model of each scenario and, by its running in FlexSim, the relevant results have been measured and collected in form of data [2]. As above - mentioned, the ISO 11228 - 3:2007 suggests analysing these results to evaluate whether the ergonomic risk may occur, more specifically according to the following three steps [6] [7]:

\section{A. Step 1}

This first step evaluates the overall number of technical actions that are performed by an operator in the real manufacturing cycles. A technical action is a movement, gesture or posture that the operator must perform, since its start, with continuity until its end. In order to complete a task, the completion of more than one technical action may be necessary.

The evaluation of the actual technical actions has been achieved according to these sub-steps:

- Step 1.1: measuring of the throughput rates of each workstation by the results of the simulation.

- Step 1.2: evaluation of the number of technical actions of each workstation that must be performed by the operator to produce a single motor.

- Step 1.3: calculation of the frequency of the technical actions of each workstation.

- $\quad$ Step 1.4: calculation of the number of technical actions per shift that has been performed at each workstation.

- Step 1.5: calculation of the overall number of technical actions per operator, that has been achieved during the shift, by the sum of the number of the technical actions performed at each of the workstation assigned to him.

In so doing, the result of the throughput rates is here graphically reported in Fig. 13 in terms of their percentages, achieved by each scenario that has been simulated. The correspondence between the workstations and their rates is expressed as the level of completion of the processes along the line, described as their percentage already completed.

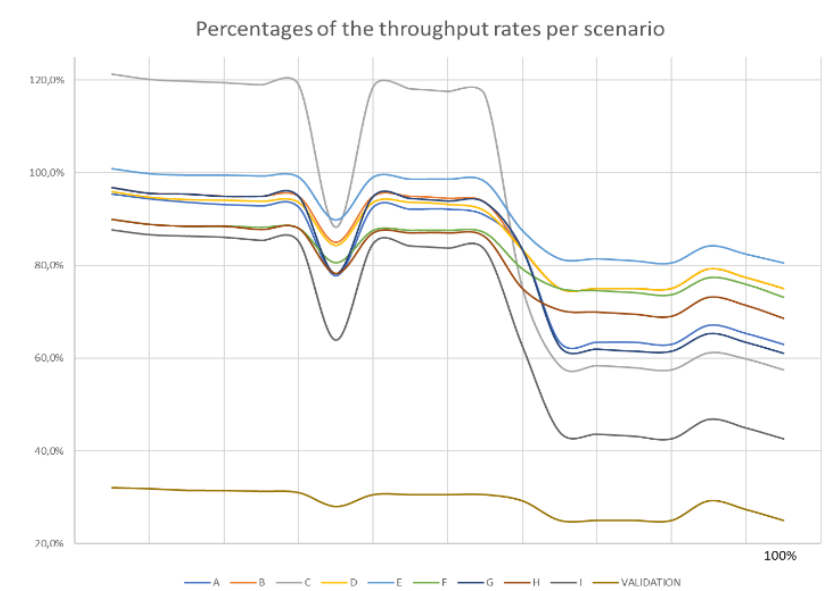

Fig. 13. Percentages of the throughput rates per scenarios.

The throughput rates reported in the previous image, measured by the simulations, have been compared with the relevant ideal percentages stated by design. As a matter of fact, some of these values are higher than $100 \%$, stating that the capability allowed to the workstation by that scenario achieves better productivities that the expected.

Although the values of the throughput rates are provided by the results of the simulations, passing by the step 1.2 a deeper analysis is required in terms of the specific number of technical actions that each output implies at each workstation.

Since each workstation requires the completion of a scheduled sequence of tasks, some of them to be performed only by the machine, those manuals have been divided in their singular technical actions, as reported in the following Table III that is just an example, for a generic workstation, of this analysis.

Table III: Types of technical actions related to a generic workstation.

\begin{tabular}{|c|}
\hline Generic workstation \\
\hline Type of technical action \\
\hline Traceability of the components \\
\hline Loading of the components \\
\hline Handling of the components \\
\hline Placement of the components \\
\hline Working action \\
\hline
\end{tabular}

Published By: \& Sciences Publication (C) Copyright: All rights reserved. 


\begin{tabular}{|c|}
\hline Cheking test \\
\hline Unloading of the final assembly \\
\hline
\end{tabular}

As shown, examples of technical actions are the manual procedures for the working or the loading of products.

The numbers of technical actions, needed for the manufacturing of a single product or subassembly, have been multiplied with the frequency of throughput of their relevant workstations to calculate their overall quantity achieved by each workstation during the shift.

The results are graphically shown in Fig. 14 and in Fig. 15.

Dimensionless number of actual technical actions per workstation during the shift

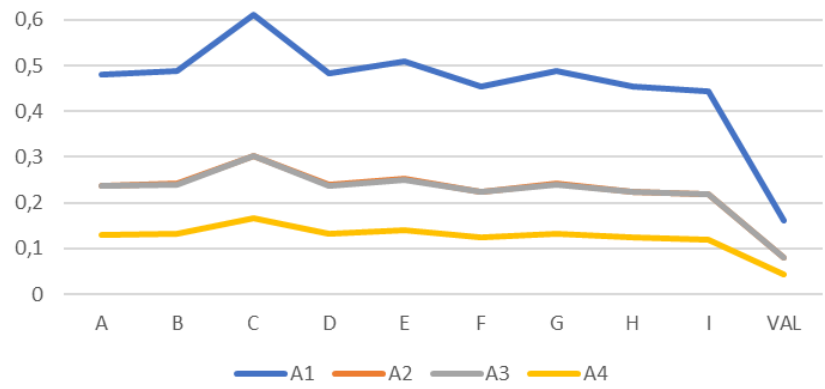

Fig. 14. Graphical of the number of actual technical actions per workstation characterized by high frequencies.

Dimensionless number of actual technical actions per workstation during the shift

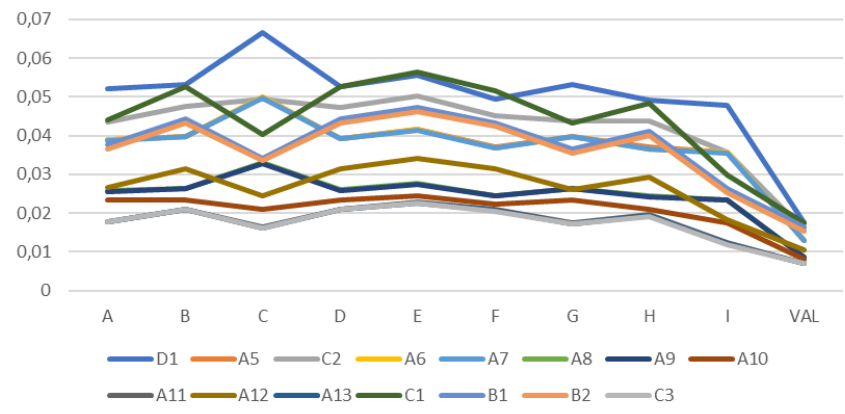

Fig. 15. Graphical of the number of actual technical actions per workstation characterized by medium and low frequencies.

The overall number of actual technical actions, performed during the shift by the operator, has been quantified summing the overall number of actual technical actions of his relevant workstations [6] [7]. The results are provided for each operator of each scenario in the following Error! Reference source not found..

Table IV: Results of the step 1 related to the evaluation of the actual technical actions

Dimensionless number of actual technical actions

\begin{tabular}{|c|c|c|c|c|}
\hline Scenario & Operator 1 & Operator 2 & Operator 3 & Operator 4 \\
\hline A & 0,50 & 0,37 & 0,41 & 0,29 \\
\hline B & 0,73 & 0,49 & 0,23 & 0,19 \\
\hline C & 0,61 & 0,30 & 0,69 & 0,32 \\
\hline D & 0,74 & 0,47 & 0,40 & \\
\hline E & 0,57 & 0,65 & 0,35 & 0,14 \\
\hline F & 0,90 & 0,42 & 0,21 & \\
\hline
\end{tabular}

\begin{tabular}{|c|c|c|c|l|}
$\mathbf{G}$ & 0,73 & 0,55 & 0,31 & \\
\hline $\mathbf{H}$ & 0,90 & 0,49 & 0,13 & \\
\hline $\mathbf{I}$ & 1,00 & 0,39 & & \\
\hline Validation & 0,54 & & & \\
\hline
\end{tabular}

These results can be graphically described by the following diagram of Fig. 16.

Dimensionless number of actual technical actions per operator

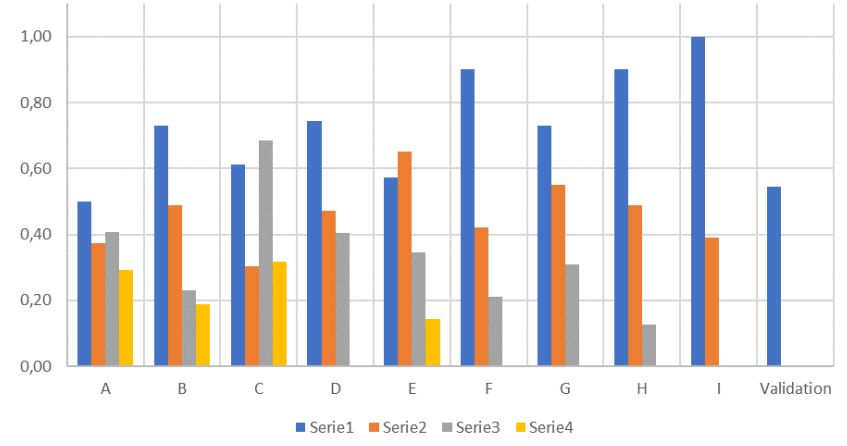

Fig. 16. Number of actual technical actions performed by each operator.

\section{B. Step 2}

The second step of the ISO 11228 - 3:2007 evaluates the number of reference technical actions. Even though the technical actions maintain their previous meaning, are here considered as those of references according to the introduction of corrective factors, whose aim is the evaluation of different aspects of each working condition.

As a matter of fact, the only quantity of actions does not allow the evaluation of their quality, that must be taken into account to assure a reliable estimation of the levels of risk that may be related to. First of all, these risks are due to the actions that must be performed at each workstation and are strictly dependent on its characteristics, such as its specific cycle of manufacturing and its level of automatization, but may be also due to the specific scenario.

The effects of the different allocations of the resources required by the scenarios are here under scrutiny for the balancing of the line. The activities may imply different types of risk and, for this reason, adequate coefficients, called multipliers, have been specifically stated to quantify each one of the following conditions:

- Multiplier related to different uses of the force. The force multiplier quantifies the forces applied, during the cycle time, by the operator in terms of their values, speeds and frequencies of execution.

- Multiplier for the postures and movements evaluated as awkward. The multiplier of posture and movement depends on the presence or absence of uncomfortable postures that may be assumed or awkward gestures that may be made by the operator to complete his tasks.

- Repetitiveness multiplier: the repetition of a task may be risky even though it hasn't been evaluated as hazardous according to the previous two coefficients. In this instance, this multiplier evaluates the adequacy of the tasks according to their frequency required by each workstation. 
- Additional multiplier: the evaluation about the effects due to the requirements of high accuracy, localized compression and the use of personal protective equipment that may imply an additional difficulty, have been quantified by the use of this multiplier.

More specifically, all these parameters strictly depend on the technical actions of each workstation and, since their description has already been provided for each task, the next step necessary for this analysis is the evaluation of the percentage of the cycle time occupied by each of them. Furthermore, since the technical actions of the tasks have been stated during the design of the line, this evaluation can be managed without the use of the simulation.

Using the above - mentioned extract of the generic workstation, the analysis is here reported in Table $\mathrm{V}$ with the integration of the percentages of the cycle time quantified for each technical action.

Table V: Types of technical actions to be performed at the generic workstation evaluated according to the ISO standard parameters.

\begin{tabular}{|l|l|l|l|l|l|}
\hline \multicolumn{1}{|c|}{ Type of technical action } & Force & $\begin{array}{l}\text { Posture and } \\
\text { movements }\end{array}$ & $\begin{array}{l}\text { Additional } \\
\text { factors }\end{array}$ & Repetitiveness & Percentage of cycle time \\
\hline Traceability of the components & No & No & No & Absent & $<1 \%$ \\
\hline Loading of the components & No & No & No & Absent & $1,2 \%$ \\
\hline Handling of the components & No & Hand pinch & No & Present & $43,5 \%$ \\
\hline Placement of the components & No & Hand pinch & Accuracy & Present & $3,6 \%$ \\
\hline Working action & No & Hand pinch & $\begin{array}{l}\text { Compression } \\
\text { and accuracy }\end{array}$ & Present & $21,8 \%$ \\
\hline Cheking test & No & No & No & Present & $18,1 \%$ \\
\hline Unloading of the final assembly & No & Hand pinch & No & Present & $10,9 \%$ \\
\hline Overall percentage per factor & $0 \%$ & $79,8 \%$ & $25,4 \%$ & $97,9 \%$ & \\
\hline
\end{tabular}

The overall estimation of the parameters has been reported in the following Fig. 17 and expressed related to the workstations as the relevant percentage of completion of the line.

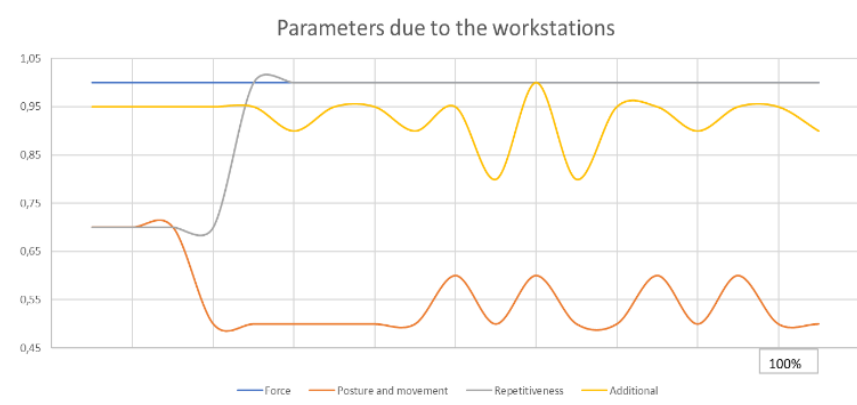

Fig. 17. Parameters due to the workstations.

However, two other multipliers must be estimated to complete the set of coefficients required by the ISO standard, and are here reported:

- Recovery multiplier: it verifies the scheduling of adequate periods for the recovery of the operators and, according to the stated limits, these pauses must have an enough duration and frequency during the shift. Furthermore, the ISO standard considers all the visual controls managed by the operator as recovery actions.

- Duration multiplier: it depends on the duration of each is measured to verify its compliance with the ISO limits. Differently to the previous ones, these two parameters need the completion of the simulation because they are function of the number of hours in which their requirements have been respected. As a matter of fact, the recovery index has been calculated by the use of the idle rate of the operator, whereas the duration has been evaluated by the utilization rate reduced by that of travelling. repetitive task which duration, being an unwanted event,

The extract of the generic workstation is here reported in Table VI related to the result of the evaluation of its parameters.

Table VI: Overall evaluation of the parameters of the generic workstation.

\begin{tabular}{|c|c|}
\hline \multicolumn{2}{|c|}{ Generic workstation } \\
\hline Name of the parameter (abbreviation) & Value \\
\hline Force multiplier $\left(F_{M}\right)$ & 1 \\
\hline Posture and movements multiplier $\left(P_{M}\right)$ & 0,7 \\
\hline Repetitiveness multiplier $\left(R_{e M}\right)$ & 0,7 \\
\hline Additional multiplier $\left(A_{M}\right)$ & 0,95 \\
\hline Recovery multiplier $\left(R_{C M}\right)$ & 1 \\
\hline Duration multiplier $\left(t_{M}\right)$ & 1,1 \\
\hline
\end{tabular}

All the above - mentioned procedures are indispensable for the evaluation of the number of reference technical actions by the use of two formulas that differ according the following conditions:

- Monotask job: a job can be defined as monotask in case the operator is expected to perform the same type of action during the entire shift. Having the repetition of the same technical action, whose duration is expressed in minutes and indicated with the letter " $t$ ", the reference number can be calculate by means of (1) [6].

$$
n_{R T A}=k_{f} \times F_{M} \times P_{M} \times R_{e M} \times A_{M} \times t \times R_{c M} \times t_{M}
$$

- Multitask job: on the contrary, a multitask job requires the operator to work on different tasks during the shift. In this instance, a clear example of the multitasks job is the management of one or more than one workstation by the operator.

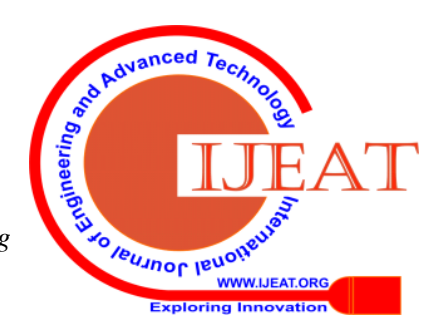


The relevant formula (2) contains the sum of the contributions of each task [6].

$$
\begin{aligned}
& n_{R T A}=\sum_{j=1}^{n}\left[k_{f} \times\left(F_{M j} \times P_{M j} \times R_{e M j} \times A_{M j}\right) \times t_{j}\right] \times \\
& \left(R_{C M} \times t_{M}\right)
\end{aligned}
$$

As clearly reported in the scenarios, the operators deal with more than one workstation and, for this, the formula of the multitask job has been used and its results are here reported in the following Table VII [6] [7].

Table VII: Dimensionless number of refence technical actions identified as the result of the step 2 . Dimensionless number of reference technical actions

\begin{tabular}{|c|c|c|c|c|}
\hline Scenario & $\begin{array}{c}\text { Operator } \\
\mathbf{1}\end{array}$ & $\begin{array}{c}\text { Operator } \\
\mathbf{2}\end{array}$ & $\begin{array}{c}\text { Operator } \\
\mathbf{3}\end{array}$ & $\begin{array}{c}\text { Operator } \\
\mathbf{4}\end{array}$ \\
\hline A & 0,35 & 0,26 & 0,29 & 0,19 \\
\hline B & 0,51 & 0,31 & 0,17 & 0,14 \\
\hline C & 0,43 & 0,21 & 0,45 & 0,23 \\
\hline D & 0,52 & 0,33 & 0,27 & \\
\hline E & 0,40 & 0,46 & 0,22 & 0,10 \\
\hline F & 0,63 & 0,27 & 0,16 & \\
\hline G & 0,51 & 0,36 & 0,26 & \\
\hline H & 0,63 & 0,33 & 0,09 & \\
\hline I & 0,67 & 0,28 & & \\
\hline Validation & 0,38 & & & \\
\hline
\end{tabular}

\section{Step 3}

The third step concludes the application of the ISO 11228 - 3:2007 with the evaluation of the above-mentioned stressing conditions quantifying the unique parameter OCRA, acronym of Occupational Repetitive Action, by the division between the number of actual technical actions, provided by the step 1 , and the number of reference technical actions, provided by the step 2, multiplying them to the normalizing factor equal to 5136, as the highest number of technical actions measured. This value must be compared with those of the standard to classify the working condition of the operator according to the absence, the possible presence or the remarkable evidence of the ergonomic risks. The classification of the level of risk of the OCRA index is based on three ranges of values related to a specific label:

- $\quad$ OCRA index lower than 2,2: there is no risk and the label associated is green.

- $\quad$ OCRA index between 2,3 and 3,5: there is a low risk and the label associated is yellow.

- $\quad$ OCRA index higher than 3,5: there is a high risk and the label associated is red. The result of the previous classification is reported in the following. Table VIII [6] [7].

\begin{tabular}{|c|c|c|c|c|}
\hline \multicolumn{5}{|c|}{ OCRA indexes } \\
\hline Scenario & Operator 1 & Operator 2 & Operator 3 & Operator 4 \\
\hline A & 1,29 & 0,95 & 3,03 & 1,38 \\
\hline B & 1,50 & 1,04 & 1,22 & 1,19 \\
\hline C & 1,42 & 0,95 & 31,69 & 1,96 \\
\hline D & 1,47 & 1,17 & 1,45 & \\
\hline $\mathbf{E}$ & 1,35 & 0,95 & 1,46 & 1,22 \\
\hline $\mathbf{F}$ & 2,66 & 1,27 & 1,17 & \\
\hline G & 1,46 & 1,02 & 1,70 & \\
\hline$H$ & 2,66 & 1,46 & 1,13 & \\
\hline 1 & 175,37 & 1,82 & & \\
\hline Validation & 145,58 & & & \\
\hline
\end{tabular}

Table VIII: Results of the step 3 of the ISO standard.

These results have been evaluated according to the following principles:

- Low risk: those scenarios with all the OCRA indexes pointed out with a green label are considered as characterized by a low risk. In this case, each scenario is considered as completely acceptable.

- Medium risk: those scenarios with at least an OCRA index pointed out with a yellow label are considered as characterized by a medium risk. In this case, each scenario is considered as sufficiently adequate, but still not to be preferred to the first ones.

- High risk: those scenarios with at least an OCRA index pointed out with a red label must be considered as characterized by a high risk. In this case, each scenario must be considered as absolutely inadequate, and it mustn't be taken into account for other applications.

For the above-mentioned reasons, the following scenarios have been selected to be deeply analyzed:

- A, B, C and E scenarios: in which four operators have been employed.

- D, F, G and H scenarios: in which three operators have been employed.

\section{Balancing parameters}

The further method, not included in the ISO 11228-3:2007 and that has been introduced to verify whether the scenario is balanced, is the measure of the variability between the OCRA indexes of the same scenario by the "balancing parameter", defined as the difference between the maximum and the minimum value of the OCRA indexes. Since the productivities of the operators are not considered by this ISO standard, the academic team has provided a key-concept about the evaluation of the line: even though the semi automated line has already been evaluated in term of the ergonomic of the stationary conditions, that are strictly related to the time spent at the workstations, the non-stationary conditions haven't been defined neither considered. So, the purpose regards the evaluation of the travelling activities mainly because capable of:

- Occupying the operators in activities afar from their workstations.

- Forcing the operators to cover distances even in case of adequate ergonomic risk.

And for these reasons capable of reducing their productivities. The balancing parameter has been evaluated according to the classification reported in Table IX.

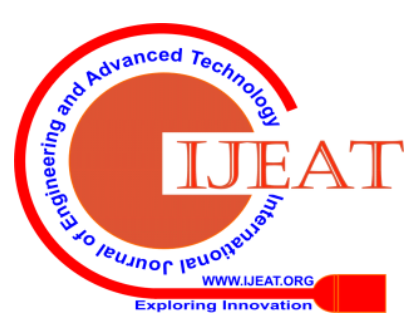


Sizing and Balancing of a Semi-Automated Line for Automotive Electric Motors by Means of Ergonomic and Performance Analysis

Table IX: Evaluation table of the balancing parameters.

\begin{tabular}{|c|c|}
\hline Range of values of balancing parameters & Score \\
\hline from 0 to 0,2 & 10 \\
\hline from 0,2 to 0,4 & 9 \\
\hline from 0,4 to 0,6 & 8 \\
\hline from 0,6 to 0,8 & 7 \\
\hline from 0,8 to 1,0 & 6 \\
\hline from 1,0 to 1,2 & 5 \\
\hline from 1,2 to 1,4 & 4 \\
\hline from 1,4 to 1,6 & 3 \\
\hline from 1,6 to 1,8 & 2 \\
\hline from 1,8 to 2,1 & 1 \\
\hline higher than 2,1 & 0 \\
\hline
\end{tabular}

And the results of the evaluation of the balancing parameters are reported in the following Table $\mathrm{X}$.

Table X: Result of the evaluation of the scenarios through the balancing parameters.

\begin{tabular}{|l|l|l|l|l|l|l|l|l|}
\hline Scenario & A & B & C & D & E & F & G & H \\
\hline $\begin{array}{l}\text { Balancing } \\
\text { parameter }\end{array}$ & 2,08 & 0,47 & 1,01 & 0,29 & 0,51 & 1,50 & 0,68 & 1,53 \\
\hline Score & 1 & 8 & 5 & 9 & 8 & 3 & 7 & 3 \\
\hline
\end{tabular}

As above - mentioned, even though eight scenarios have been considered as adequate according to the ergonomic evaluation of the ISO standard, their performance must be evaluated in order to identify those with the highest productivity.

As stated in the introduction of this paper, these results of the ergonomic analysis of the working conditions do not guarantee the highest performance achievable by the semi automated line, and the achievement of a complying rate of productivity of the line is paramount to guarantee the manufacturing rates that the workstations have been designed to provide.

The studies of the productivities have been based on two approaches, both based on the purposes of the team to achieve an overall estimation of the performance that are due to the mechanical and the human factors. In this instance, in the following reports, the quantifying of both the contribution are made by the use of specific table, developed for their evaluation.

\section{E. Productivities of the machines}

As for the evaluation of the balancing parameters, also the productivities of the machines have been evaluated according to the ranges of values reported in Table XI.

Table XI: Evaluation table of the productivity of the machines.

\begin{tabular}{|c|c|}
\hline Range of values of productivity & Score \\
\hline from $97,5 \%$ to $100,0 \%$ & 10 \\
\hline from $95,0 \%$ to $97,5 \%$ & 9 \\
\hline from $92,5 \%$ to $95,0 \%$ & 8 \\
\hline from $90,0 \%$ to $92,5 \%$ & 7 \\
\hline from $87,5 \%$ to $90,0 \%$ & 6 \\
\hline from $85,0 \%$ to $87,5 \%$ & 5 \\
\hline from $82,5 \%$ to $85,0 \%$ & 4 \\
\hline from $80,0 \%$ to $82,5 \%$ & 3 \\
\hline
\end{tabular}

\begin{tabular}{|c|c|} 
from $77,5 \%$ to $80,0 \%$ & 2 \\
\hline from $75,0 \%$ to $77,5 \%$ & 1 \\
\hline lower than $75,0 \%$ & 0 \\
\hline
\end{tabular}

Considering the same workstation of assembling used as the example in the previous sections, its productivity achieved at each scenario is here reported in Fig. 18.

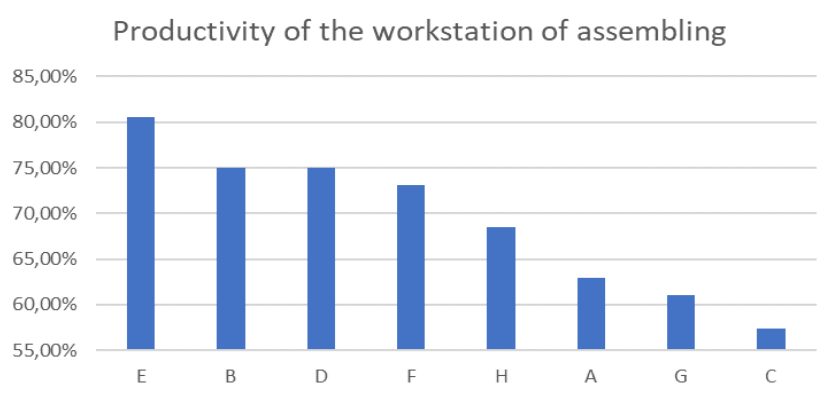

Fig. 18. Diagram of the productivity of the workstation of assembling.

\section{F. Productivities of the operators}

A deeper analysis is provided by adding to the previous data those considering the travels. Even though the semi-automated line has been designed to be inserted in a layout of a laboratory, the sizes of the machines, of their equipment and of their auxiliaries occupy a significant area. This may cause paths of work too extended for operators that are continuously expected to complete tasks at the machines, and that may be forced to cover high distance even in unstressed conditions. Since the ISO standard does not take into account any aspect of the travelling activities, the present work has been extended to the overall distance that each operator covers during his shift, that has been quantified by the simulation for each scenario and evaluated by the following Table XII.

And the dimensionless distance covered by the operators during the shift of each scenario is reported in Fig. 19.

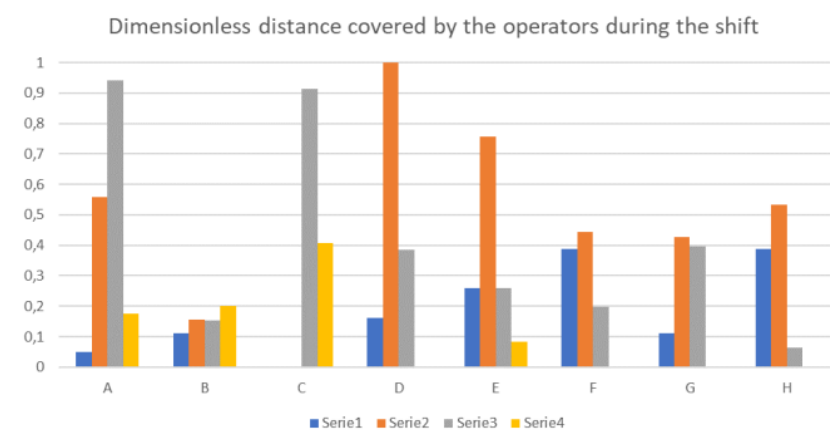

Fig. 19. Overall travelling dimensionless distances covered by each operator per scenario and during the shift.

As shown in the figure, the B scenario is the only one in which the operators cover overall distances during the shift that may be considered quite similar each other.

More specifically, the evaluation of the distances covered by the operators has been managed by the comparison among the evaluation table above - 
mentioned and the results of the multiplication between each dimensionless distance and the normalizing factor equal to 17430 , that is the highest distance, expressed in meters, that has been measured by the software of simulation during the shift.

\section{FINAL RESULTS}

All the above - quantified results, that have been based on the method of the ISO 11228-3:2007, on the balancing parameter, on the comparison with the expected productivities and on the data coming from the software of simulation, are here used to conclude the present study of the semi - automated line of the INPROVES project for the manufacturing of brushless motors for the automotive application providing the following Fig. 20 related to the classification of the scenarios.

\section{CLASSIFICATION OF THE SCENARIOS}

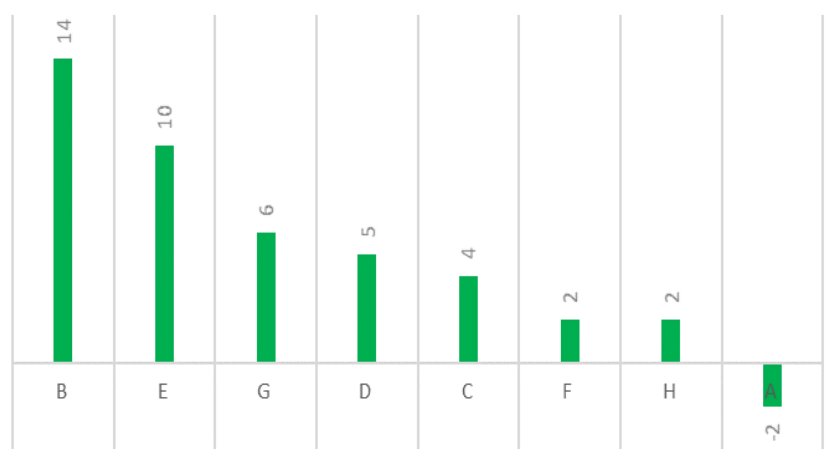

Fig. 20. Classification of the scenarios

The classification has been achieved summing the quantitative results of all the steps of the analysis, as those of simulation by FlexSim, of the three steps of the ISO standard, of the balancing evaluation of the scenarios, of the productivities of the operators and of the machines, and of the distances covered by the operators. This has allowed the identification of the best scenario as the B because capable of organizing and assigning the tasks of the semi-automated line satisfying the requirements of balancing and sizing.

Table XII: Evaluation table of the overall distances covered by the operators.

Table for the evaluation of the distances covered by the operators

\begin{tabular}{|c|c|c|c|c|c|}
\hline from & to & $\begin{array}{c}\text { Sco } \\
\text { re }\end{array}$ & from & to & Score \\
\hline 0 & 500 & $\mathbf{1 0}$ & 4000 & 4500 & $\mathbf{2}$ \\
\hline 500 & 1000 & $\mathbf{9}$ & 4500 & 5000 & $\mathbf{1}$ \\
\hline 1000 & 1500 & $\mathbf{8}$ & 5000 & 6000 & $\mathbf{- 1}$ \\
\hline 1500 & 2000 & $\mathbf{7}$ & 6000 & 7000 & $-\mathbf{2}$ \\
\hline 2000 & 2500 & $\mathbf{6}$ & 7000 & 8000 & $-\mathbf{3}$ \\
\hline 2500 & 3000 & $\mathbf{5}$ & 8000 & 10000 & $-\mathbf{5}$ \\
\hline 3000 & 3500 & $\mathbf{4}$ & \multicolumn{2}{|l}{} & $-\mathbf{7}$ \\
\hline 3500 & 4000 & $\mathbf{3}$ & \multicolumn{3}{|l}{}
\end{tabular}

Furthermore, even though all the working conditions belonging to these scenarios have been defined as adequate according to the ergonomic risk described in the ISO
11228-3:2007, it is clearly evident the huge difference among them as the result of the introduction of the methods of analysis related to the evaluation of the balancing parameters and the productivities of operators and of machines.

As a matter of fact, this difference is particularly well notable providing the comparison between the best and the worst scenario, that are the $\mathrm{B}$ and the $\mathrm{A}$ and whose relevant diagrams are reported in Fig. 4 and Fig. 3 respectively.

Even though both the images describe a shift scheduled with the same number of operators and the same operators have been assigned with a number of workstations not significantly different, on the contrary the effect on the level of balancing and on the production rates are significantly different.

Talking about the distribution of the productivities of the workstations, described by Fig. 21, the green diagram shows how the production rates of the machine in the $\mathrm{B}$ scenario achieve higher levels than those of the A scenario.

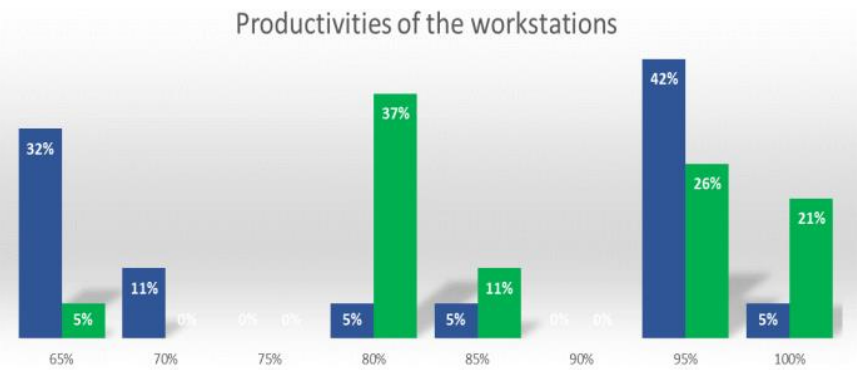

Fig. 21. Distribution of productivities of workstations.

In particular, the percentages highlighted in the bars represents how many stations have the productivity indicated by the abscissa axis. The motivations that have led this distribution cannot be easily found because of the complex interweaving already described and that is one of the reasons why FlexSim simulation software has been introduced However, it is still possible to comment that the main visible difference that solutions $\mathrm{B}$ and $\mathrm{A}$ have is the different assignment of the workstations to each operator rather than their number.

As a matter of fact, the alternance in the Process Flowchart of contiguous workstations not assigned to the same resource might have led to an unbalanced situation in which an operator might have had to wait the completion of the tasks of another one; furthermore, this unbalancing might have been also due to the level of automatization of the workstations that the operators have had to deal with.

What has been previously mentioned about the balancing has been partially described by the measures made by the simulation software on the distances covered by the operators, that are reported in form of percentages in the following Fig. 22 and Fig. 23.

Published By:

Blue Eyes Intelligence Engineering \& Sciences Publication

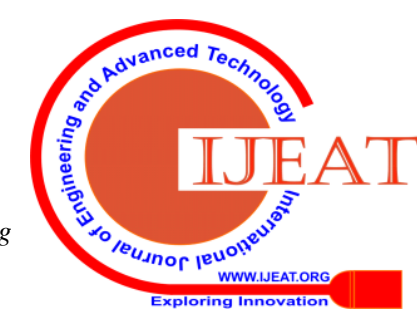




\section{TRAVELLING PARTITIONING SCENARIO B}

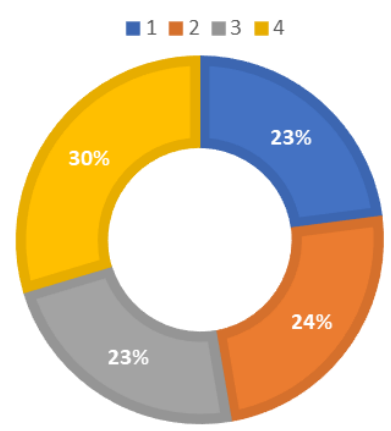

Fig. 22. Percentage distribution of the travelling tasks among the operator of the scenario $B$

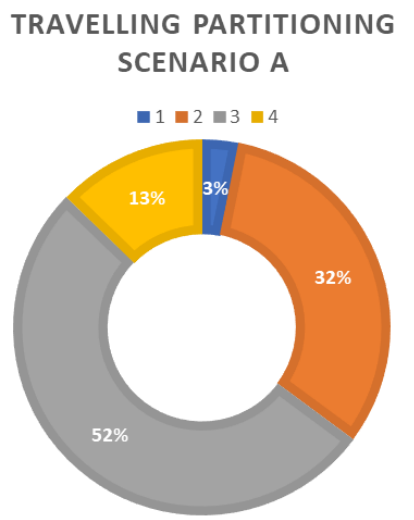

Fig. 23. Percentage distribution of the travelling tasks among the operator of the scenario A

Such diagrams indicate the partitioning of the overall travelling time among the operators of the two scenarios, in which the solution $\mathrm{B}$ has been provided with an equal distribution of travelling tasks.

\section{CONCLUSION}

The present paper has led the reader to the comprehension of the main difficulties due to the implementing of a semi automated line of manufacturing and of the methods that may be used to deal with them. Through important topics, those related to the ergonomic conditions provided to the workers, due to a good scheduled shift of work, have been firstly evaluated according to the ISO standard that has quantified the unique index known as the OCRA. As a matter of fact, what has been reported in the introduction of the present paper regards the assignment of the operators to the line, whose employees cannot be simply quantified in their overall number, but, most of all, in their capacity of providing a continuous attention in what they are doing that only a well balanced working condition can guarantee. In this instance, the analysis has considered each activity as an interweaved sequence of processes, whose responsibility is under both the man and the machine behaviours and whose manufacturing cycle has been divided in its singular movements, gestures and postures and evaluated according to the comfort provided to the operators and the compliance with the manufacturing requirements of each of the brushless motor made. Numerous different assignments among operators and machines, called scenarios, have been evaluated to describe each shift of work in a software of simulation. The software has been selected because not only capable of forecasting the effects of the scenarios on the ergonomic parameters, but also because of its useful application in the further methods oriented to the evaluation of their performance, that, even though absolutely important for the overall productivity of the line, are not considered by the ISO standard.

The enhancement in the efficacy of analysis, described in the present paper, has been provided by the above mentioned further methods, in particular related, on one hand, to the distances covered due to the material handling and to the pre-emptive activities that may occur during the shift of an operator, and, on the other, to the production rates of each machine. In so doing, starting from the ergonomic requirements of the ISO standard, a more detailed procedure has been described for the balancing and the sizing of semi automated line of manufacturing.

\section{ACKNOWLEDGMENT}

The development of the activities described in the present paper have been made possible by Lombardy Region which is funding INPROVES project (Integration of product and process for manufacturing electric motors of road vehicles) according to the Line of agreements for Research and Innovation co-funded by the POR FESR 2014-2020 (CUP E36D17000090009).

\section{REFERENCES}

1. P. Righettini, R. Strada, S. Togni, A. Gosatti, F. Camozzi, C. Fissore, "Smart Mobility: a modern approach to automotive product development for vehicle electrification", 5th International Forum on Research and Technologies for Society and Industry, IEEE, September 9-12, 2019, pp 459-464.

2. L. Gong, B. Zou, Z. Kan, "Modeling and Optimization for Automobile Mixed Assembly Line in Industry 4.0”, Journal of Control Science and Engineering, Hindawi, 2019.

3. Wang, Y. R., Chen, A. N., "Production logistics simulation and optimization of industrial enterprise based on Flexsim", Int j simul model 15 (2016) 4, pp. 732 - 741.

4. T. Bartkowiak, P. Pawlewski, "Reducing negative impact of machine failures on performance of filling and packaging production line - a simulative study", Proceedings of the 2016 Winter Simulation Conference, T. M. K. Roeder, P. I. Frazier, R. Szechtman, E. Zhou, T. Huschka, and S. E. Chick, eds., IEEE, 2016, pp. 2912-2923.

5. M. Kubòn, I. Kaczmar, P. Findura, "Reliability of technical systems and the methodology for calculating MTBF using Flexsim computer simulation", E3S Web of Conferences 132, 01012 (2019), pp. 1-8.

6. UNI ISO 11228-3, "Ergonomia, Movimentazione manuale, Parte 3 : Movimentazione di bassi carichi ad alta frequenza", ISO, April 2009.

7. Technical Report ISO/TR 12295, "Ergonomia - Documento per l'applicazione delle norme ISO alla movimentazione manuale di carichi (ISO 11228-1, ISO 11228-2 e ISO 11228-3) e la valutazione delle posture di lavoro statiche (ISO 11226)", Ref. No. ISO/TR 12295:2014(E), Prima edizione, ISO, 2014

8. J. Bai, J. Pan, "The Optimization and Simulation of Automobile Production Line Based on Flexsim", 2011 International Conference on Management and Service Science, IEEE, 2011, pp. 1-3.

9. P. V. Thete, R. R. Lekurwale, "Application of Descrete - Event Simulation to Increase Throughput of Manufacturing System - A Case Study", Proceedings of International Conference on Intelligent Manufacturing and Automation, Lecture Notes in Mechanical Engineering, H. Vasudevan et al. (eds.), 2019, pp. $531-539$.

10. J. Peng, "Optimal allocation of resources in production line based on Flexsim simulation", 2010 International Conference on Management and Service Science, IEEE, 2010 .

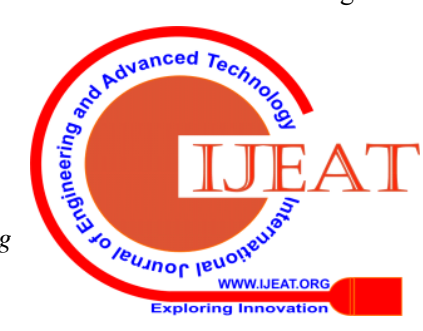


11. G. Wu, L. Yao, S. Yu, "Simulation and optimization of production line based on Flexsim", Proceeding of the $30^{\text {th }}$ Chinese Control and Decision Conference, CCDC 2018, IEEE, 2018, pp. 3358 - 3363.

12. R. J. Patil, P. R. Kubade, H. B. Kulkarni, "Optimization of machine shop layout by using Flexsim software", $1^{\text {st }}$ International Conference of Manufacturing, Material Science and Engineering (ICMMSE - 2019), AIP conference proceedings, 2019, Vol. 2200.

13. N. Kruethi, S. Chaijit, W. Permpoonsinsup, D. Thongkot, A. H. Ismail, P. Srinoi, "A simulation model to improve the efficiency of painting robots and applied an engineering economic for project selection", 2019 Seventeenth International Conference in ICT and Knowledge Engineering, IEEE, 2019.

14. A. Ge, Y. Zhang, "Research on optimization for balance of BSP model assembly line based on Flexsim", Proceedings of the $3^{\text {rd }}$ International Conference on Information Management, Innovation Management and Industrial Engineerign, ICIII, IEEE, 2010, Vol. 2, pp 272 - 276.

15. G.V. Punna Rao, S. Nallusamy, P. Raman, "Enhancement of production in subassembly line of a medium scale industry using different lean tools and Flexsim simulation software", International journal of engineering research in Africa, Trans Tech Publications Ltd, 2019, Vol. 44, pp 229-239.

\section{AUTHORS PROFILE}

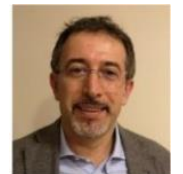

Paolo Righettini was born in Salò, Italy, in 1966. He received the Master degree in Mechanical Engineer in 1991 from Politecnico di Milano. In 1994 he became Assistant Professor of Applied Mechanics at Politecnico di Milano. In 2000 he became Associate professor at Politecnico di Milano; subsequently, he moved to the Università degli Studi di Bergamo where, since 2007 he has been Associate Professor at the School of Engineering. Here he is the head of the mechatronic research group and head of the Mechatronics and Mechanical Systems Dynamics laboratory. His research activities mainly concern the dynamic modelling and the control of mechatronic systems, kinematic and dynamic synthesis of robotic devices, kinematic synthesis and dynamic control of parallel kinematic robots. In these contests, he has interest in the modelling and control of electrical, hydraulic and piezoelectrical actuating systems. The research activities regard both the theoretical/numerical part and the experimental one

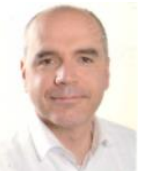

Roberto Strada was Born in Vimercate, Italy, in 1969. He received the Master degree in Mechanical Engineering at Politecnico di Milano in 1994. In 2001 he got the PhD degree in Applied Mechanics at Politecnico di Milano. Since 2002 he has been Assistant Professor of Applied Mechanics at the School of Engineering of the Università degli Studi di Bergamo. His research activities mainly concern the dynamic modelling and simulation of driving systems for Mechatronics; in particular, the activity deals with the study of the dynamic characteristics of systems and components driven by hydraulic actuators, pneumatic actuators and electric actuators. Besides theoretical and numerical analysis, experimental activities have been performed. Results of the research activities have been published in international journals and presented at international conferences.

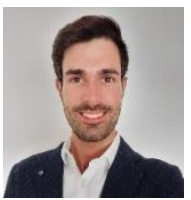

Stefano Togni was born in Ponte San Pietro, Italy, in 1993. He received the Bachelor's degree in Mechanical Engineering at Politecnico di Milano in 2016 and the Master's degree in Mechanical Engineering at the Università degli Studi di Bergamo in 2018. Since 2019 he has been Research fellow at the Università degli Studi di Bergamo belonging, at first, to the Centre for Innovation and Technology Transfer, then to the Department of Engineering and Applied Sciences. His research activities mainly concern the development of brushless motors for the vehicles's braking systems and of their relevant semi - automated line of manufacturing for the Automotive Industry; in particular, the research activity focuses on the analysis of the behaviour of the mechanical devices of the machines, on their software modelling for the Failure Modes and Effects Analysis, taking into account the effects of the failures of both the machine and the human factors on the products, and for the simulations of the production processes, oriented to the sizing and the balancing of the line for the prototyping and manufacturing activities. The research activity deals also with the analysis of the ergonomic condition of the workers by the use of the ISO standard in addition to the solutions developed for their evaluation.

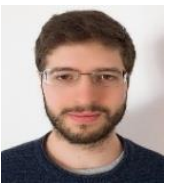

Filippo Cortinovis was born in Bergamo, Italy, in 1992 he obtained a Master degree in Mechanical Engineering at the University of Bergamo in 2019. Since then he received a research grant related to the development of methods and configurations for the coordination of multi-robot machines for assembly and components' handling. Within this context he pursued activities concerning dynamic modelling of parallel manipulators, motion control, and applications of reinforcement learning algorithms to the management of automated production systems.

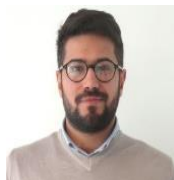

Cristiano Fissore Master Degree at Politecnico di Torino in Mechanical Engineering. 7 year of experience in process development for the Automotive applications. From 3 years in Brembo spa as reference for Industrialization and Process development in the projects of Advance R\&D teams. Responsible for Brembo Industrialization for project INPROVES

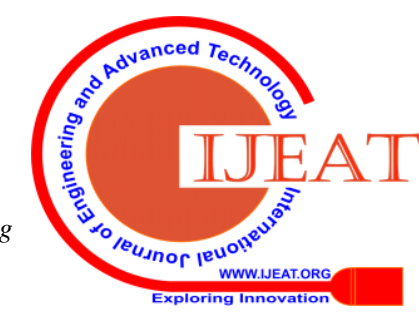

